\title{
The Future of Telecommunications
}

\author{
DOI 10.1007/s12599-011-0178-0
}

\section{The Authors}

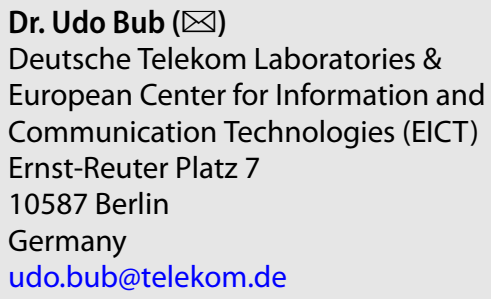

Prof. Dr. Dres. h. c. Arnold Picot Ludwig-Maximilians-Universität München

Ludwigstr. 28

80539 München

Germany

picot@Imu.de

\section{Prof. Dr. Helmut Krcmar}

Technische Universität München

Boltzmannstr. 3

85748 Garching

Germany

krcmar@in.tum.de

Published online: 2011-09-07

This article is also available in German in print and via http://www. wirtschaftsinformatik.de: Bub U, Picot A, Krcmar H (2011) Die Zukunft der Telekommunikation. WIRTSCHAFTSINFORMATIK. doi: 10.1007/s11576-0110290-2.

(C) Gabler Verlag 2011
For two decades the telecommunications industry has been facing severe changes caused by the growing dominance of the Internet architecture as general purpose communications infrastructure, mass media, and also by new generations for mobile communications. This development will continue: new network technologies (e.g. Next Generation Networks, Long Term Evolution) will change cost and market structures, innovation cycles for products and technologies will become shorter, value chains will change.

This is illustrated by vendors entering online service markets or offering their own network communication through so-called managed services. The change of operations system platforms and the emergence of application market places, especially in the mobile domain with the so-called apps, influence the future development considerably. Established network operators, on the other hand, start to specify individual consumer devices; classic computer manufacturers break into the telecommunications market by way of consumer devices as well as new services. The acquisition of Motorola Mobility by Google is only one further indicator that this ecosystem is subject to fundamental change.

As sign of emancipation from services and infrastructure, numerous new enterprises offer carrier agnostic telecommunications and data services without owning the infrastructure, so-called over the top providers. Along with this a gradual shift of shares of the value chain with neighboring industries such as the media industry can be observed.

Information technology (IT) and the next generation of telecommunications - based on the Internet protocol IP supporting services as well as the infrastructure - will get more and more similar. This is why many IT paradigms will become transferable to the telecommunications infrastructure. The growing convergence is coined by the term information and communications technology (ICT).

Operators are often faced with the decision if they should build their future on pure network operations or seek premiums through new types of network specific services (using so-called enablers) or network agnostic services, respectively. The development of the telecommunications industry and the impulses and innovations caused by it in business and society depend considerably from the institutional guidelines, especially from regulations. The controversially discussed topic of network neutrality, i.e. the equal treatment of all Internet traffic allows for different views on the same thing: network neutrality can be interpreted as productive or counterproductive to innovation.

In any case the internal operations of the involved players have to be designed very effectively and efficiently to reach a higher degree of automation. This is where reference models such as the Enhanced Telecom Operations Map (eTOM) help to reach a standardized course of action when needed. The harmonization between business processes and enterprise information systems along with a well tuned enterprise architecture plays a crucial role here.

Further new challenges offer opportunities, but require a thorough techno-economical investigation. The current network transformation to an IP-based infrastructure of the Next Generation Networks offers potential for increased efficiency, but also requires high investments of billions of Euros with various decision alternatives. The started rollout of fiber optics connection right into homes (Fiber To The Home) will not only offer bandwidth of well over $100 \mathrm{Mbit} / \mathrm{s}$ to end customers, but will also give operators new opportunities to shape the network architecture, as well as to further automate the internal business processes up to a zero touch (i.e. fully automated) provisioning of services. This enormous build-out will not be done by former monopolies (so-called incumbents) alone, but will be shared. The business models of infrastructure suppliers will require a mutual ability for wholesale. This implies that in the future, incumbents might also lease some access capacity from other operators, which was not the case before. In addition to that it turns out that in some geographical regions public spending might be necessary (e.g. by means of Public-Private-Partnerships) in order to achieve full coverage of high speed broadband access.

It all sums up to the fact that innovative products and applications have to be found that are convincing to the customer both in functionality and price. As a matter of 
fact a central innovation approach targets business models that take into account the interplay of customer needs and technical feasibility at affordable costs.

Technological change, industry change, and newly arising user trends affect each other and as a matter of fact ICT changes society. In a broad long term project these developments have been investigated qualitatively and quantitatively within the scope of an international Delphi study (Münchner Kreis et al. 2010) within the process of the German national IT summit of the government. So far the study has been conducted in three extensive phases with the results available for free download, the latter two volumes also in English language.

This focus issue is dedicated to research work with regard to the Future of Telecommunications. The high repercussion of the topic resulted in 19 submissions of which we have selected four in up to four review rounds. Further, of these submissions we could select the State-of-the-Art contribution for this focus issue. Some of the rejected papers were recommended for resubmission to the regular issues of this journal.

The high quality of the contributions was assured by numerous reviewers from inside and outside of the editorial board and we would like to thank for their dedicated work. Special thanks to Marten Schönherr, Philipp Offermann, Nico Grove, and Christoph Riedl.

It turned out that the majority of contributions are based on empirical research paradigms. This is only due to the higher quality of the scientific implementation of these specific projects. The editors also welcome in the same way design science methods when carried out with the same scientific rigor.

In the first research paper Marcel Fritz, Christian Schlereth and Stefan Figge investigate empirically a new tariff for mobile data services taking into account a changing market and cost structure in telecommunications. They argue that new mobile technologies should be introduced with the goal of cost optimization as opposed to higher willingness to pay in contrast to strategies in the past.

Building on earlier work Torsten Gerpott and Sabrina Berg tackle the readiness of consumers to adopt mobile location based services. They test newly developed hypotheses in a survey and derive influences on the individuals to use such offering. The results indicate amongst others that the reputation of the service in the users' social environment is very crucial whereas privacy and cost concerns are less important with respect to the usage.

Two further research papers deal with changing value chains.

Jochen Wulf and Rüdiger Zarnekow analyze the inter-industry diversifications in the ICT market. They identify a high competition with media industry as well as high diversification of the software industry. Based on these findings the authors derive potentials and risks for the design of future competitive strategies of telecommunications companies.

Considering new structures of value chains, Key Pouttchi and Yvonne Hufenbach develop a reference model for providers of mobile services. They investigate their service portfolio as well as the portfolio of other market participants and identify the currently existing and the future shares of the value chain. Based on these finding a new reference model for the future mobile services market is found which serves as the basis for the development of future scenarios.

The contribution to the State-of-the-Art category deals as well with the focus topic of this issue. Rahul Basole and Jürgen Karla analyze ecosystem structures for the operations systems platforms of mobile devices, especially for smartphones. They argue that these mobile platforms have considerable influence on the future of the industry and visualize the development of the worldwide market structure. They consider the market segments of mobile device manufacturers, mobile network operators, mobile application developers, and mobile platform providers. Based on the observation of the past five years the authors consider the involved strategies and provide implications for the ecosystem of the future.

Regarding the Interview we have set up a new format to tackle the controversial subject of network neutrality. With Marvin Ammori and Christof Weinhardt we have invited two experts and opinion leaders who offer their differentiated view on this multilayered topic introducing also diverging standpoints. We have asked them to answer separately to the identical set of questions and as such close the focus topic "the future of telecommunications" with the comparison of the answers.

With the publication of this focus issue we would like to link our goal to further open up the discipline of Business and Information Systems Engineering (BISE) to the topics 
of telecommunications and Internet in a more and more networked world of society, business, and technology. Especially regarding the convergence of information, communication, and media technology, BISE offers key elements for further exploitation of this subject matter with its theories, concepts, models, methods, and tools.

Taking this into account we want to stimulate even more scientific activity towards techno-economical research questions around services and infrastructure in the area of communication and networking. Contributions based on both empirical and design science methods to technology, architecture, processes, design, operations, business models and market structures are welcome equally.

\section{References}

Münchner Kreis e.V. et al. (eds) (2010) Prospects and opportunities of information and communication technologies (ICT) and media. http://www.future-ict.de. Accessed 2011-07-31 